\title{
Cal Poly's mullimedia approach to research
}

\author{
By Paul T. Adalian Jr.
}

\section{Graphics make Retriever an enticing research experience}

D uring the past few years, libraries such as Ohio State University and Cornell University have sought to develop library instruction programs to teach the elements of a search strategy, and access to local paper and automated sources. ${ }^{1}$ The California Polytechnic State University Library has taken this idea one step further by developing a multisensory, multimedia application for teaching the use of print and Internet-accessible sources.

Known as the Retriever, the program is a colorful user interface providing library users with a complete learning environment to identify and locate print sources, and to access local and remote online databases. The interface utilizes color, QuickTime ${ }^{\mathrm{TM}}$ video clips, scanned images, line drawings, floor plans, and creative graphics to provide students with an enticing research experience.

\section{DEVELOPING THE CONCEPT}

The program was developed for first-time library users to help them navigate through the research process at their own pace, yet seasoned users will appreciate how quickly and easily they can access specific sources of information.

The Retriever development was based on meeting the two basic information needs of students at Cal Poly. First, every student needs to complete a senior project as a graduation requirement. The one requirement of all senior project students is to conduct a comprehensive review of the literature. Many students have not used the library enough to be familiar with the concept of a literature review. The Retriever was designed to take students through this process within specific majors.

Second, Cal Poly has an applied curriculum. Students require information in conjunction with study and research in labs, field work, architecture and engineering design studios, printing and graphic art studios, etc. Students are building, creating, and designing projects. Within this context students are not required to write the typical term paper. Rather, they require reference information to be incorporated into their applied study.

The "Looking for Information In" window meets the needs of literature review; the "Reference Sources On" window provides access to relevant references used within the major.

Macromind Director ${ }^{\mathrm{TM}}$ was used to develop the interface. The Director program provides color, enhanced graphic capability, compatibility with Macintosh and IBM platforms, reliability, self-running players (royalty-free distribution), sophisticated multimedia features such as animation, QuickTime ${ }^{\mathrm{TM}}$, and a serial Port XObject for emulating a modem telecommunications program.

\section{THREE COMPONENTS OF THE SYSTEM}

All three components of the system are displayed on the introductory screen (figure 1).

Online Resource links users to local and remote online databases with the click of a button. Once connected, the Retriever program provides a searching environment that guides students to utilize the full capabilities of each online system.

The discipline-specific section, Online/Print Resources for Papers and Senior. Projects in Spe- 


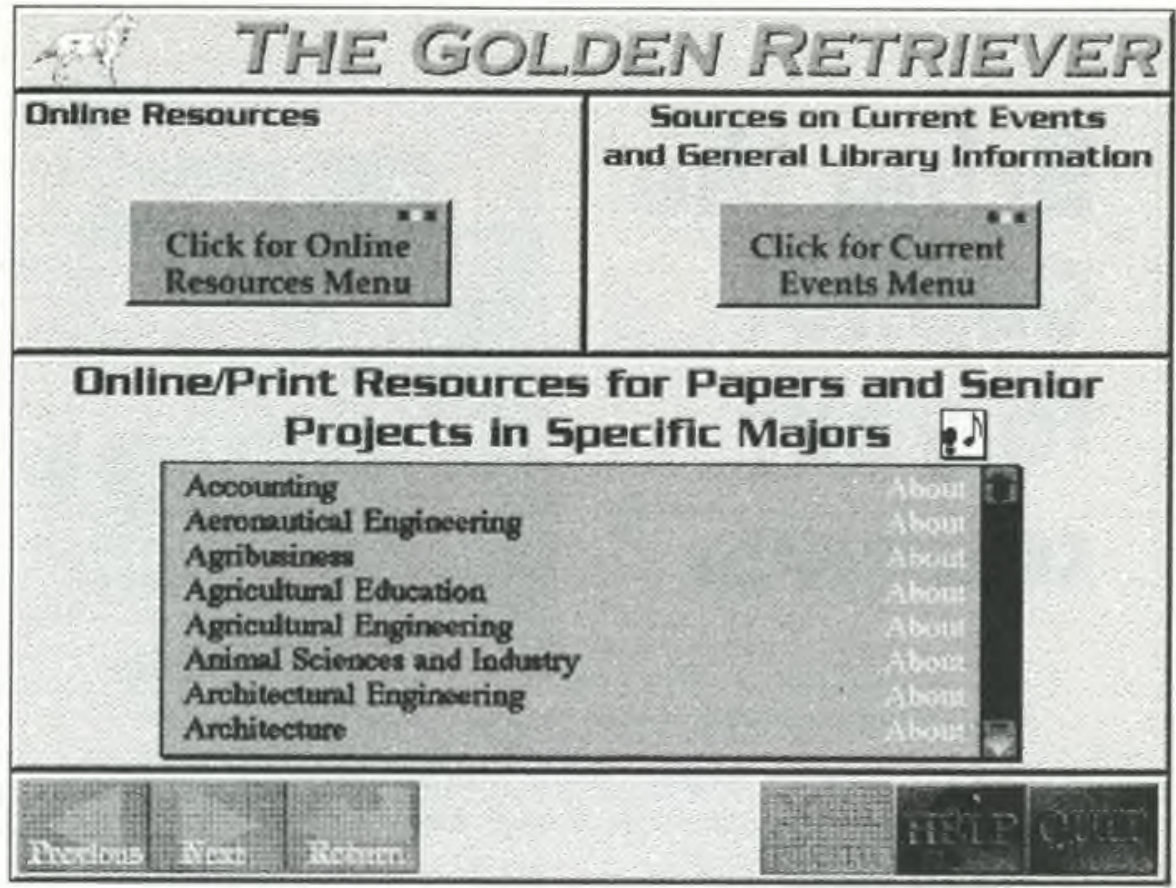

Figure 1. Introductory screen.

cific Majors, links students to print and online sources for every major on campus.

Sources on Current Events and General Library Information provides access to print and online resources for writing papers on current event topics, and answering frequently asked questions.

Directional information was not included on the interface since there is a touch screen information kiosk near the stations.

\section{Online Sources}

"Online Sources" (figure 2) is a simple menu providing 11 options for the user to connect quickly to local or remote online databases. The About button provides information about each of the databases, while descriptions give a general overview, strengths and weaknesses, and tips on why and when they should be used.

This menu interacts with Cal Poly's gopher server to make the initial connection. Scripting in Macromind Director ${ }^{\mathrm{TM}}$ takes the user to a specific screen within the database.

When a database is selected, a 3D-rendered splash screen appears while the program is preparing to connect. Scanned images and graphics provide a colorful introduction to the source.
Once connected, the program provides a searching environment that guides the beginning students to the beginning and advanced searching features of the system, while the experienced user can use all the quick features and commands with which they are familiar.

The vt100 screen of the database is displayed (figure 3). To the right and at the bottom of the vt100 screen are a series of buttons and help options. On-screen help, step-by-step instructions, and advanced searching prompts can be selected and viewed while the host clatabase is displayed (figure 4).

Students are encouraged to use advanced features of each database. In addition, students are guided to broaden or narrow a search by selecting buttons labelled Can't Find Enough and Found Too Much.

A QuickSearch option is also available for each database that makes it simple to enter the search statement along with selected search limiters and other advanced features (figure 5).

Users can print screen by screen, or save the search results to a notepad. Once results are saved in the notepad, users have the choice of printing the results, forwarding the results to their e-mail account, or downloading if the student is using the system re- 

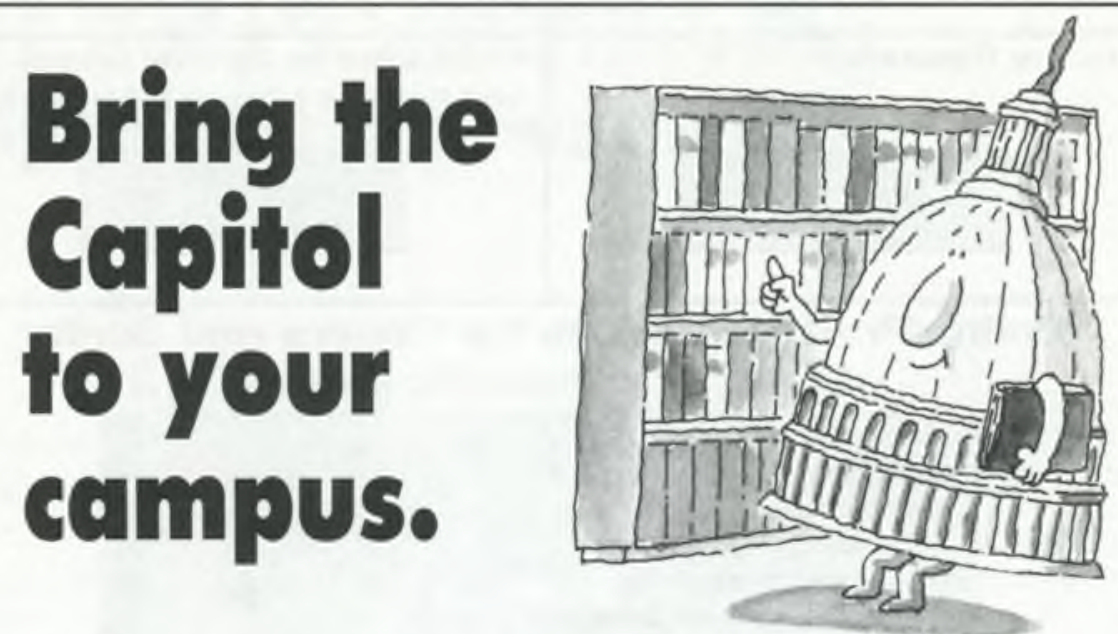

With Congressional Quarterly publications and services.

The CQ Weekly Report keeps your faculty and students upto-date with objective coverage of each week's congressional action.

The CQ Researcher offers in-depth background, analysis, chronology and bibliographies on one hot topic each week.

With CQ's Washington Alert, your campus has online access to texts of bills, documents, transcripts, CQ publications and much more.

Call now for more information on CQ publications and services and put your campus in the thick of congressional action!

For FREE SAMPLES of
print publications or information on
CQ's Washington Alert, stop by booth
243-245 at the ACRL National Conference!

\section{Or call:}

Vickie Binsted at (800) 432-2250 ext. 279, or (202) 887-6279, for print publications.

Waldo Tibbetts at (800) $432-2250$ ext. 350, or (202) 887-6350, for CQ's Washington Alert.

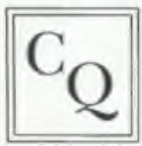

Congressional Quarterly 1414 22nd Street N.W.

Washington, D.C. 20037 
motely. Students can also save their search strings for later use.

The interfaces to each of these online sources can also be accessed through the disciplineoriented section below.

\section{Online/print resources ... in specific majors}

Every major at Cal Poly is listed on this scroll window (see figure 1). This section links students to print and online sources in specific subject disciplines. This module was designed so students could relate to the unique information needs of their majors.

In addition to each major, the following disciplines were included: law, medicine, women's studies, and ethnic studies. The resources in these fields are used extensively by students and faculty even though there are no formal degree programs.

Once a major is selected, a colorful 3D-rendered splash screen representing the major appears. After the graphic dissolves, the primary screen for the major is displayed (figure 6). The name of the major appears in a large bold type font at the top of the screen. There are three windows. The two top windows contain information from which students can select. The bottom empty window is a large area to display the results from selecting options from one of the top two windows.

The top left window is titled "Reference Sources On." This scrolling window provides a listing of information needs for the major. The information needs were identified by subject specialist librarians.

Twenty or less categories were included for most majors. Terminology used by students and professionals in the field was selected to describe the information needs. Library terminology such as subject dictionaries, directories, handbooks, and manu- als, etc., are not used within this window. However, these terms are used within annotations and introductory notes to various sections.

Once an information need is selected, a list of sources or a step-by-step search strategy is displayed.

Students can simply browse through this window and become bibliographically aware of the information needs within their field, along with sources that are available

Once a relevant source is found, students have the option to click on the floor plan button (figure 6) to display a colorful floor plan of the department where the source is located. Moving footprints on the floor plan lead students to the location of the source.

Students can also click on the video screen (figure 6) to see a QuickTime ${ }^{\mathrm{TM}}$ movie of the area containing the source

Users can print information or save the results of an entire session to a notepad for future printing or forwarding to individual e-mail accounts. Floor plans can be printed, but not downloaded, to e-mail accounts.

The top right window is titled "Looking for Information In" and is also a scrolling window containing three different sections.

First, the How to Get Started option provides students with basic descriptions of the "Reference Sources On" and "Looking for Information In" windows, and the large display window. It provides a quick overview of how each

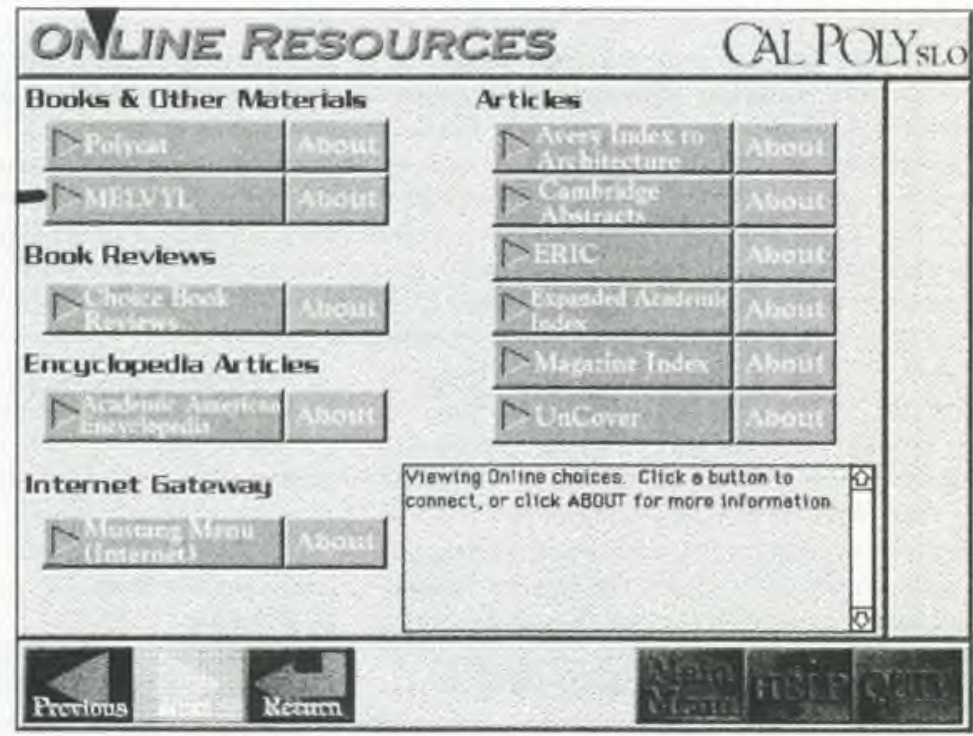

Figure 2. Online Resources screen. 


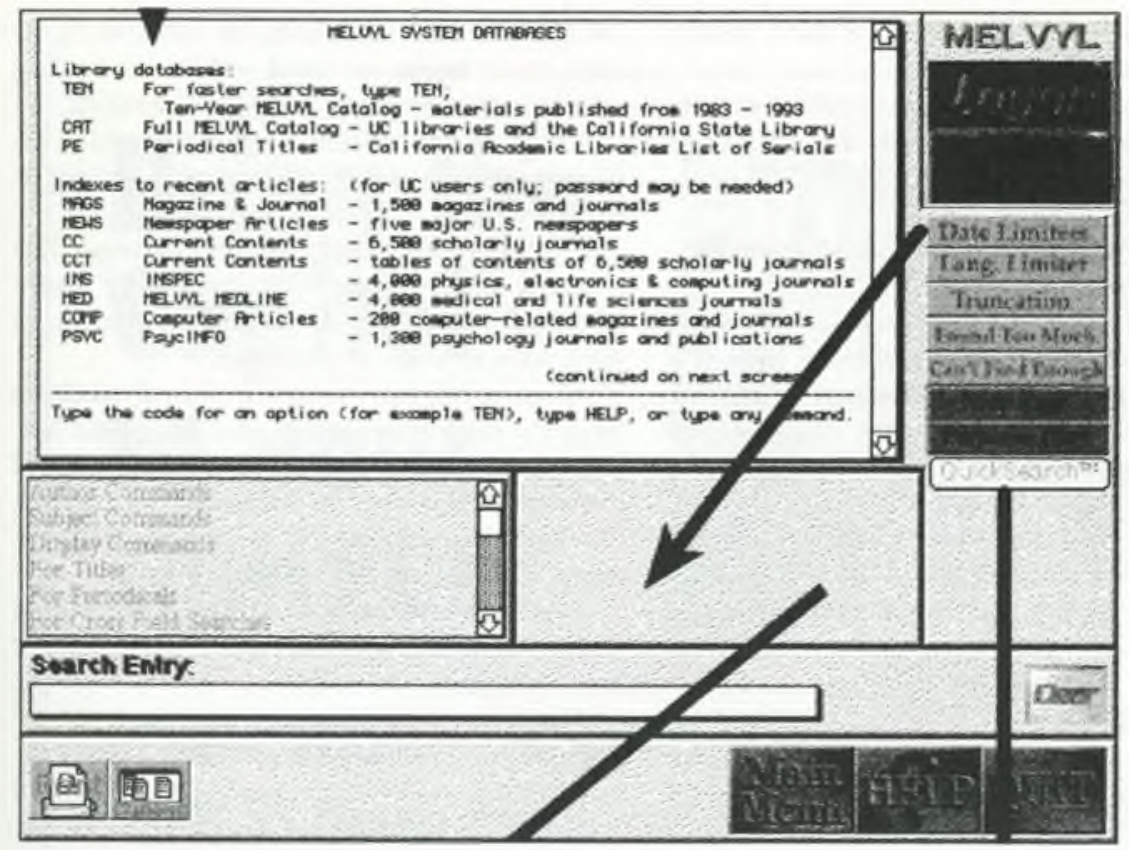

LIMIT BY DATE

After entering a search stemement in the seanch vitudow use a date liniter o namov search nesults to more pecent publications by nsing the DATE LTMITER command.

$O$ and date recent $=$ lavsit 3 yeazs $\mathrm{O}$ and date carrent $=100 \mathrm{t} 10$ ytacs.

\section{Cancel}

\section{OK}

Figures 3 and 4. Search and Limit by Date screens. subject-oriented section is structured and how to navigate through both windows easily.

Second, A Review of the Literature gives a definition of a literature review, the finished product of a literature review, how the literature review relates to students' research through graphic images, and the steps to take in the review. It demonstrates how to find relevant information in books, periodical articles, government documents, senior projects, and any other literature relevant to the discipline. Graphics are used extensively to provide students with a visual step-by-step process.

The remainder of the selections in the "Looking for Information In" window are devoted to various types of literature. Finding books, journal articles, newspaper articles, government publications, and other types of literature relevant to each major is presented. Subject specialists determined the types of literature to be included in this window.
Once Books is selected, a brief introductory sentence about the types of books that can be found within the major appears in the large scrolling window at the bottom of the screen.

Each section (type of literature) has a similar introductory sentence. This gives students a point of reference of the literature type, and directs them to information in their field.

After the introductory statement is read, a click of the down arrow displays a screen describing Polycat, Cal Poly's online catalog, along with a button that connects directly to our OPAC. Each online source selected has an interface as described in Online Sources above. Once logged off, the student will return to the screen of his or her major (figure 6).

A click on the down arrow after Polycat is selected takes students to a similar screen introducing MELVYL (the University of California's online catalog), which also has a button that will directly connect to MELVYL. LIBS and Hytelnet are also in the system, and explanations are provided about their usefulness.

Materials found at other libraries can be saved and verified in Polycat and, if not found, e-mailed to Cal Poly's Interlibrary Loan and Document Delivery Department. 
The Articles section contains both print and online indexing and abstracting services relevant to the major. Print sources contain a citation and a summary of contents. Students can click the floor plan icon and/or the video screen icons to see the location and a video clip of the source's location. Remote online indexes are also listed and can be connected to in a similar fashion. For example, in architecture, students will see a number of print indexes (Art Index, Architectural Index, Architectural Periodicals Index, etc.) and online sources (UnCover, Magazine Index, and Avery Index to Architectural Periodicals, etc.).

Senior Projects and Master's Theses (if a major has a graduate program) are also listed. By clicking on either of these two categories, students can connect to Polycat, and the search is already formulated to select all senior projects or master's theses in the major. Then students are guided to narrow the results to find relevant hits.

\section{Current events and basic library information}

This section helps students identify frequently requested general information such as current events, scholarships, resumes, graduate schools, book reviews, film reviews, etc. Sources include specific online and print tools accompanied by search strategies to use for the writing of a paper on a current social, political, economic, or international topic.

\section{REMOTE ACCESS}

Current plans call for selling disks of the system at a nominal price. Disks will include specific majors and colleges within the university, but will not include video clips. The XObjects of Macromind Director ${ }^{\mathrm{TM}}$ will make the connection to a gopher, and contain royalty-free run-time versions. The disks can be produced for both Macintosh and IBM compatibles. In the future, full versions on CDs of the system are aiso planned.

Options to enhance networking capabilities that would facilitate higher transfer speeds of large multimedia files utilizing a server are also being explored.

\section{SUBJECT AND MULTIMEDIA SPECIALISTS}

Subject specialists within the Reference Department worked on each of the discipline-specific sections of the interface. Reference librarians include: Sharon Fujitani (agriculture), Lynne Gamble (humanities \& social sciences), Wayne Montgomery (computer science \& human-ities), Gertrude O'Neill (art \& foreign languages), Lane Page (business), Eileen Pritchard (sciences), Jay Waddell (engineering), and Paul Adalian (architecture).

Jeff Delarm, the multimedia specialist, was responsible for the authoring side of the project. He conceptualized and designed all graphical aspects, plus implemented all levels of interactivity and scripting.

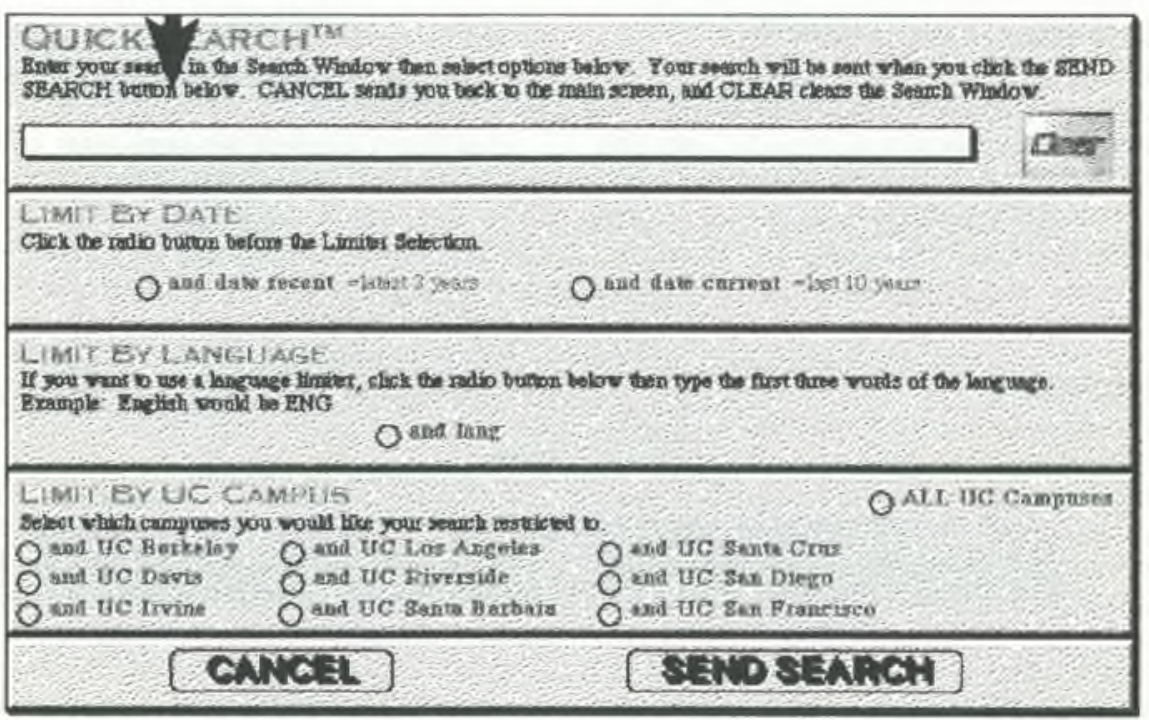

Figure 5. Quicksearch screen. 


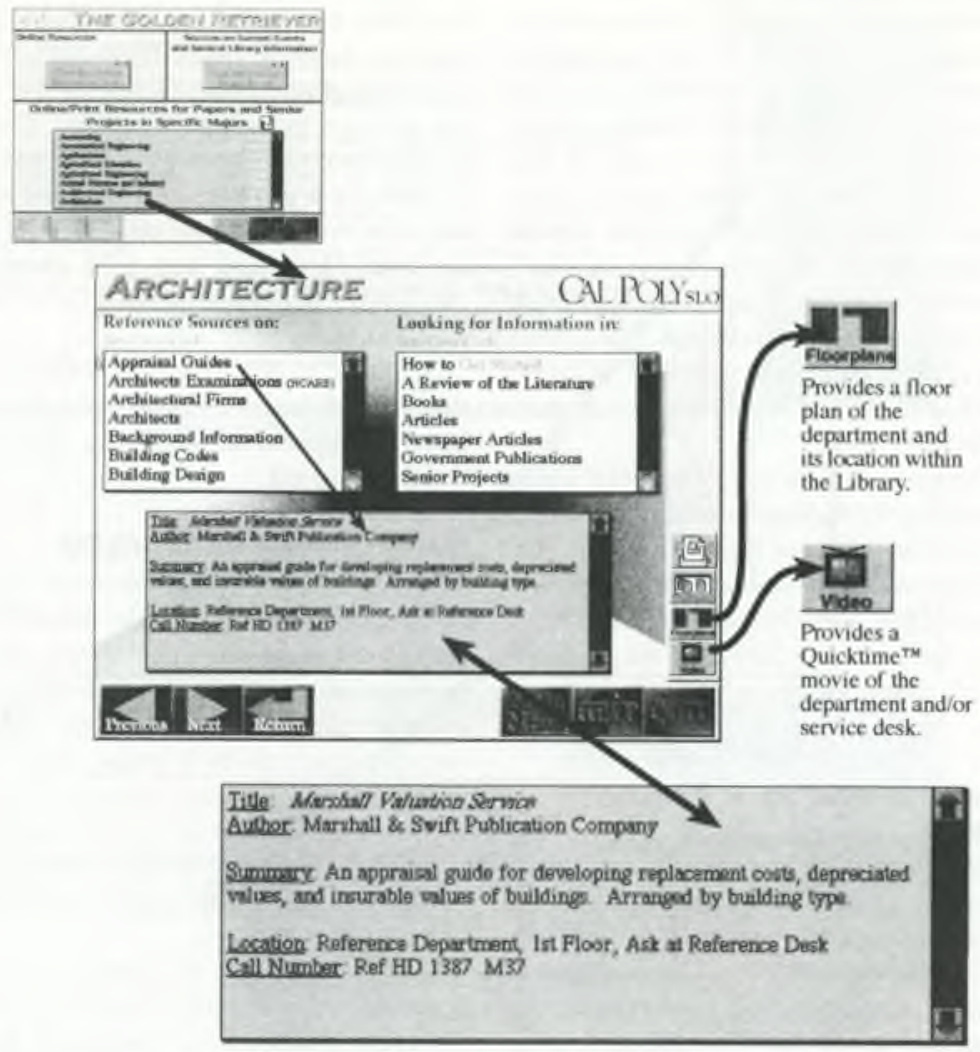

Figure 6. Reference Sources On screen.

\section{OTHER USE OF MACROMIND DIRECTOR $^{\text {TM }}$}

Macromind Director ${ }^{\mathrm{TM}}$ is currently being used as the Kennedy Library's multimedia authoring environment. Modules have been developed for a touch screen information kiosk, classroom multimedia presentations, CAI modules for specific online and print sources, in addition to the Retriever.

\section{FUNDING}

Two campus grants were received to develop the Retriever. The first one was a small research grant to study the feasibility of such a project. A second grant for multimedia development was used to hire student assistants, and to purchase hardware and software. These two grants combined for a total of $\$ 23,000$.

Apple Computer Inc. provided us with the hardware (a Macintosh IIfx) and software for the initial development. Apple also provided us with an external hard drive so the Retriever and other multimedia projects could be demonstrated easily.

The library funded the remainder of the project by hiring a half-time multimedia specialist. In addition, the library purchased projection equipment and requisite hardware for developing classroom multimedia projects and an information kiosk.

We have spent only $\$ 55,000$ thus far for the Retriever and all other multimedia projects.

\section{Note}

1. Philip J. Smith and Virginia Tiefel, "The Information Gateway: Designing a Front-End Interface to Enhance Library Instruction," Reference Services Review 20:4 (1992): 37-48; Susan J. Barnes, "Award Winning Mann Library Showcases Its Electronic Gateway," Computers in Libraries 13:8 (September 1993): $12+$. 


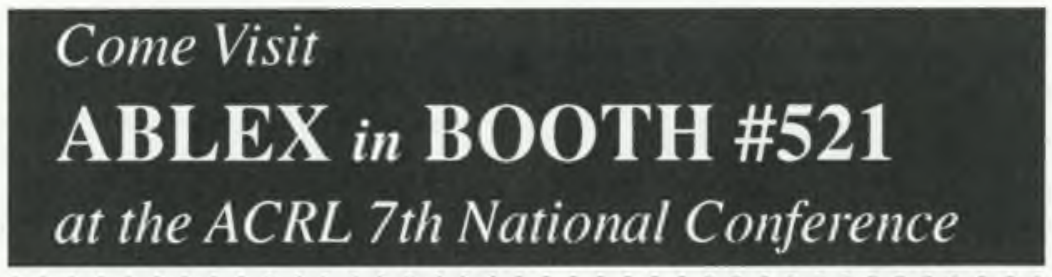

SEEKING MEANING:

\section{A Process Approach to Library and Information Services Carol Collier Kuhlthau, Rutgers University}

A Volume in the Information Management, Policies and Services Series This volume presents a theoretical framework for a process approach to library and information services, describing a series of studies of the information search process of users that indicate a need for counseling in the process of information seeking.

$$
\text { Published } 1993 / 232 \text { pages }
$$

Cloth: 0-89391-968-3/\$45.00 - Paper: 1-56750-019-6/\$24.50

\section{Librarianship: The Erosion of a Woman's Profession}

Roma Harris, University of Western Ontario

A Volume in the Information Management, Policies and Services Series This book addresses such issues as the change that librarianship is going through due to pressures generated from within the profession as well as to shifts in the economy. Also, the fact that, for more than 100 years, library work in North America has been women's work and women have been attempting to enhance their status to conform more with the model of professionalism exhibited by traditionally male fields such as medicine and law.

Published 1992 / 192 pages Cloth: 0-89391-840-7 / \$39.50 - Paper: 0-89391-941-1 / \$22.50

\section{New Revised Edition!}

Statistics: A Component of the Research Process

Peter Hernon, Simmons College

A Volume in the Information Management, Policies and Services Series This book provides a general discussion beneficial to librarians and library school students, and demonstrates the steps of the research process, decisions made in the selection of a statistical technique, how to program a computer to perform number crunching, how to compute those statistical techniques appearing most frequently in the literature of library and information sciences, and examples from the literature of the uses of different statistical techniques.

Published $1994 / 264$ pages

Cloth: 1-56750-092-7/ \$45.00 - Paper: 1-56750-093-5 / \$22.50

\section{Ablex Publishing Corp..355 Chestnut St. Norwood, N.J 076 48} (201) 767-8455/8450 FAX: (201) 767-6717 